\title{
Protective Effect of Morus Nigra Leaf Extract on Diazinon- Induced Hepatotoxicity in Rats
}

\author{
Hina Majid ${ }^{1}$, Salman Shahid ${ }^{2}$, Sadia Shakeel ${ }^{3}$, Mariam Ashraf ${ }^{4}$, Muhammad Yasoob Ali ${ }^{5}$, Amna Ahsan $^{6}$ \\ ${ }^{1}$ Assistant Professor, Department of Anatomy, Postgraduate Medical Institute Lahore, Pakistan \\ ${ }^{2}$ Audiologist, Government Special Education Department, Lahore, Pakistan \\ ${ }^{3}$ Assistant Professor, Department of Oral Biology, Postgraduate Medical Institute Lahore, Pakistan \\ ${ }^{4}$ Associate Professor, Postgraduate Medical Institute Lahore, Pakistan \\ 5 Professor \& Head, Department of Anatomy and Oral Biology, Postgraduate Medical Institute Lahore, Pakistan \\ ${ }^{6}$ Demonstrator, Department of Oral Biology, Postgraduate Medical Institute Lahore, Pakistan
}

\begin{abstract}
AB STRACT
Background: Diazinon is a globally used pesticide. Morus nigra (Black Mulberry) possesses flavonoids and phenols, which act as antioxidants. The objective of this study was to determine the possible protective effects of Morus nigra leaf extract on Diazinon-induced hepatotoxicity in rats.

Material and Methods: It was an experimental study conducted in the Department of Anatomy, Postgraduate Medical Institute, Lahore. A total of 36 healthy male Wistar albino rats were divided into three groups with 12 rats in each group. Group I was the control group. Group II was treated with $60 \mathrm{mg} / \mathrm{kg}$ body weight (bw) Diazinon daily for 4 weeks through orogastric intubation. Group III was treated with Diazinon $60 \mathrm{mg} / \mathrm{kg}$ bw daily along with $350 \mathrm{mg} / \mathrm{kg}$ bw of Morus nigra extract daily for 4 weeks through orogastric intubation. Blood samples were collected through cardiac puncture, for estimation of alanine transaminase (ALT) and aspartate transaminase (AST) levels. Liver dissection was done, slides of the hepatic tissue were prepared and studied under light microscope. The histology of hepatocytes, portal lobule, portal vein and sinuosoids was observed. SPSS 20 was used for data analysis. One-way ANOVA followed by Tukey's test was applied to establish difference among groups with $P$-value $\leq 0.05$ considered as statistically significant.

Results: Histology of Liver tissue in group I showed normal morphology while group II revealed hypertrophy and vacuolization of hepatocytes, congested central vein and sinusoids and presence of necrotic foci. These toxic effects were reversed by the co-administration of Diazinon with Morus nigra in group III which showed normal histology of the hepatic tissue. Similarly, Diazinon administration resulted in significant elevation of ALT and AST levels $(P$-value<0.05), while, Morus nigra resulted in a considerable decline in the levels of these enzymes ( $P$-value $<0.05)$.

Conclusions: Morus nigra extract has hepatoprotective effects against liver toxicity induced by Diazinon.

Key words: Alanine transaminase, Antioxidants, Aspartate transaminase, Diazinon, Morus nigra, Pesticide.

$\begin{array}{lll}\text { Authors' Contribution: } & \text { Correspondence: } & \text { Article info: } \\ { }^{1} \text { Conception; Literature research; } & \text { Hina Majid } & \text { Received: January 1, 2020 } \\ \text { manuscript design and drafting; }{ }^{2,3} \text { Critical } & \text { Email: hinamajidmir@gmail.com } & \text { Accepted: September 19, 2020 }\end{array}$

Accepted: September 19, 2020

analysis and 4-6manuscript review; Data

analysis; Manuscript Editing.
\end{abstract}

Cite this article. Majid H, Shahid S, Shakeel S, Ashraf M, Ali MY, Ahsan A. Protective Effect of Morus Nigra Leaf Extract on Diazinon-Induced Hepatotoxicity in Rats. J Islamabad Med Dental Coll. 2020; 9(3): 175-181. Doi: 10.35787/jimdc.v9i3.483
Funding Source: Nil

Conflict of Interest: Nil 


\section{Introduction}

For centuries, pesticides are used to exterminate organisms, which cause diseases in plant and to control insects, weeds, and pests in order to enhance the agricultural yield. ${ }^{1}$ Diazinon is an organophosphorus pesticide used globally. ${ }^{2}$ Humans are exposed to Diazinon through contamination of food and water by this insecticide. The residues of pesticide stick onto the leafy vegetables and fruits leading to various health hazards. Diazinon inhibits the enzyme acetylcholinesterase and activates cholinergic, muscarinic and nicotinic receptors. ${ }^{3}$ Exposure to organophosphorus insecticide causes salivation, lacrimation, nausea, vomiting, diarrhea arrhythmias, miosis, involuntary defecation, urination and arrthymias. ${ }^{4}$ Studies have reported the harmful effects of Diazinon on many organs including the brain, gonads, liver and kidneys. ${ }^{5,6}$ Diazinon affects the mitochondrial membrane transportation in the rat liver. It also disturbs cytochrome P450 system in human liver and causes changes in liver enzymes, biochemical indices and provoke mitochondria swelling. Diazinon inflicts oxidative stress by generating free radicals. ${ }^{7}$ Disproportionate production of reactive oxygen species and depletion of antioxidant capacity alters the balance and results in oxidative stress. Therefore, it makes sense to say that potentiation of antioxidant capacity can be an effective approach to attenuate the toxic effects of Diazinon. ${ }^{8}$

Morus nigra is cultivated all over the world. It is known by the name of Black Mulberry and Shahtoot. ${ }^{9}$ Morus nigra is a rich amalgam of polyphenols, flavonoids, and anthocyanins. ${ }^{10}$ The flavonoids and phenols exert strong antioxidant activity and have a protective action against oxidative damage to membranes and biomolecules. ${ }^{11}$ Flavonoids are reported to show hepatoprotective effects. ${ }^{12}$ Black Mulberry is widely used in traditional medicine to stop bleeding, to soothe pain and reduce inflammation. ${ }^{13}$

The present research aimed to study the ameliorative effects of Morus nigra on hepatotoxicity produced by Diazinon in rats to elucidate the curative potential of the plant. Morus nigra is a widely grown plant, thus it can serve as a low cost and easily available remedy for Diazinon induced hepatotoxicity and liver diseases.

\section{Material and Methods}

It was an experimental study conducted in the Department of Anatomy, Postgraduate Medical Institute Lahore, Pakistan between April 2019 to June 2019. A total of 36 healthy male Wistar albino rats were used. Sample size of 12 animals in each group was calculated using 95\% confidence level, $90 \%$ power of test and mean \pm SD for aspartate transaminase (AST) levels through Power and Precision 3.0 software. The leaves of Morus nigra were collected from Punjab University, Lahore. After drying the leaves for a week, they were powdered by a grinder and then soaked in aqueous methanol. Solution was filtered, evaporated and a gel like paste was produced. Analytical grade Diazinon PESTANAL ${ }^{\circledR}$ (CAS Number: 333-41-5) was purchased from SigmaAldrich. Ethical approval was obtained from the Ethical Committee of Postgraduate Medical Institute, Lahore, Pakistan on 29 ${ }^{\text {th }}$ April 2019.

The male Wistar albino rats (150-200 g) were acclimatized for a week and kept in the animal house of PGMI, Lahore under standard conditions. The rats were randomly sorted into three groups, each having 12 animals. Group I (Control) received distilled water $1 \mathrm{ml} / \mathrm{kg}$ for four weeks. Group II was given $60 \mathrm{mg} / \mathrm{kg}$ bw Diazinon daily using orogastric tube for 4 weeks. Group III was administered 
Diazinon $60 \mathrm{mg} / \mathrm{kg}$ bw daily along with $500 \mathrm{mg} / \mathrm{kg}$ of Morus nigra extract daily for 4 weeks through orogastric intubation. At the end of the experiment i.e. 24 hours after the last dose, rats were euthanized and cardiac puncture was done to get blood samples for the analysis of liver biochemical markers, AST and ALT. Liver dissection was done. The liver tissue was processed and paraffin blocks were prepared. Approximately $5 \mu \mathrm{m}$ thin sections were sliced, stained with Hematoxylin and Eosin and studied under a light microscope.

The histology of hepatocytes, portal lobule, portal vein and sinuosoids was observed. The levels of AST and ALT were presented as mean \pm SD. SPSS 20 was used for data analysis. One-way ANOVA followed by Turkey's test was applied to establish differences among groups. P-value $\leq 0.05$ was considered statistically significant.

\section{Results}

Histological examination of liver belonging to control group I showed normal hepatocytes and hepatic lobules. Normal Kupffer cells were seen. No congestion was observed in the central vein and sinusoids (Figure 1).

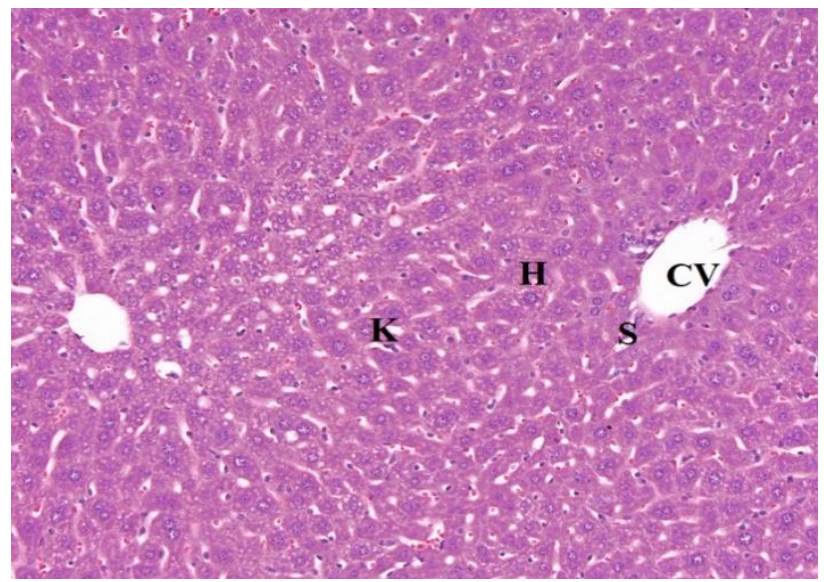

Figure 1: Photomicrograph of rat liver (group I) showing normal hepatocytes (H), normal central vein (CV) and normal sinusoidal space (S) (H\&E, 200x).

Liver histology from Group II revealed vacuolization and ballooning of majority of the hepatocytes. Some regions of the liver tissue exhibited necrosis. Many intervening hepatic blood sinusoids showed congestion. Most of Kupffer cells appeared hypertrophied. Congestion was also observed in central veins (Figure 2).

The liver sections of rats belonging to group III showed normal histological structure of the hepatic tissue. Normal parenchymal arrangement of polygonal hepatocytes was observed. The cytoplasm and the nuclei of the hepatocytes revealed no degenerative changes. Sinusoids also exhibited normal features. Kupffer cells appeared normal in size and the central veins were not congested (Figure 3).

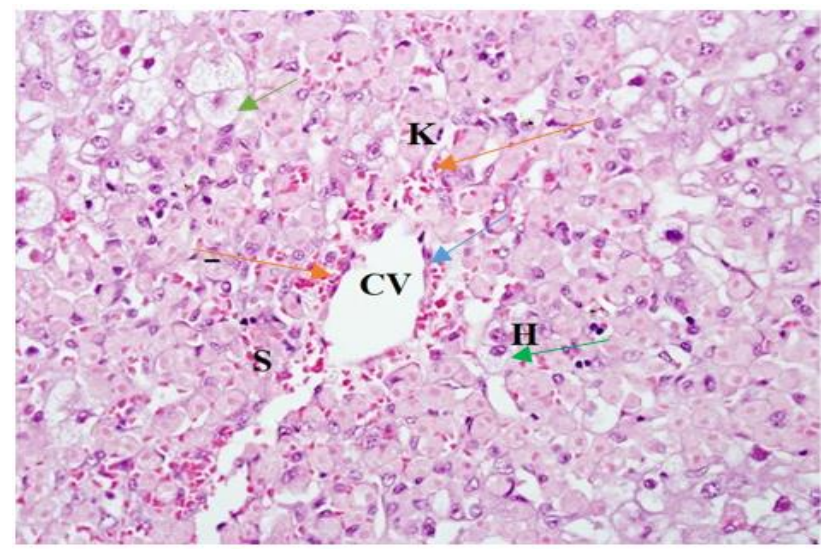

Figure 2: Photomicrograph of rat liver (group II) showing ballooning and vacuolization of hepatocytes $(H)$ (green arrows), dilated central vein (CV) (blue arrow) and congested sinusoids (S) (orange arrow) (H\&E, 200x).

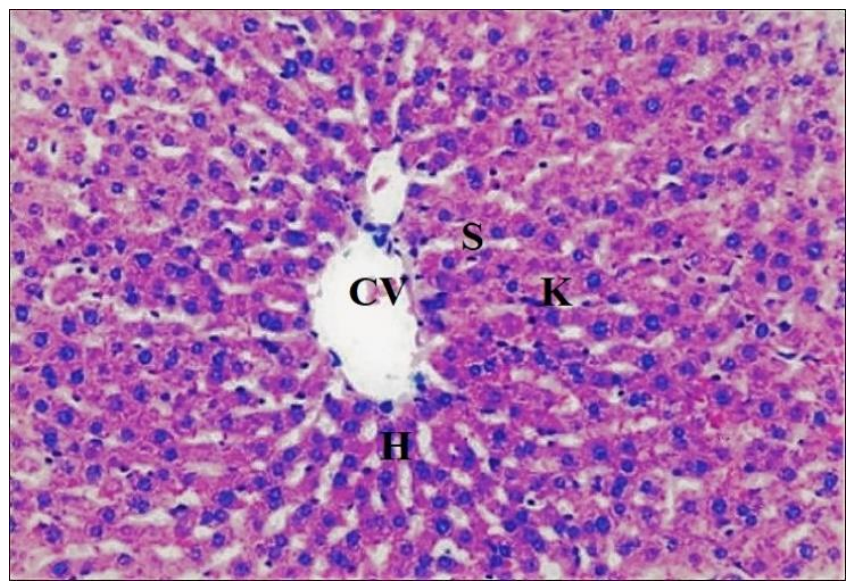

Figure 3: Photomicrograph of rat liver (group III) show ing normal hepatocytes (H), normal central vein (CV) and normal sinusoidal space (S) (H\&E, 200x). 
Levels of ALT and AST enzymes were significantly raised in the rats belonging to group II. Whereas, the co-administration of Morus nigra significantly lowered serum AST ad ALT levels (Tables I \& II).

\begin{tabular}{|l|c|c|c|c|}
\hline \multicolumn{5}{|c|}{ Table I: Comparison of ALT and AST levels among the three groups by one-way ANOVA } \\
\hline Groups & $\begin{array}{c}\text { ALT (U/L) } \\
\text { Mean } \pm \text { SD }\end{array}$ & P-value* & $\begin{array}{c}\text { AST (U/L) } \\
\text { Mean } \pm \text { SD }\end{array}$ & $P_{\text {-value* }}^{*}$ \\
\hline Group I & $32.04 \pm 11.93$ & - & $27.47 \pm 10.35$ & - \\
\hline Group II & $114.49 \pm 11.81$ & In comparison to Group I & $112.8 \pm 20.63$ & $<0.01$ \\
\hline Group III & $38.50 \pm 2.70$ & $\begin{array}{c}<0.01 \\
\text { In comparison to Group } \\
\text { II }\end{array}$ & $34.81 \pm 4.27$ & In comparison to Group I \\
\hline
\end{tabular}

ALT-Alanine transaminase; AST-Aspartate transaminase

$* P$ - value $\leq 0.05$ was considered significant

Table II: Post-hoc Tukey analysis of ALT and AST levels among groups

\begin{tabular}{|l|c|c|c|c|}
\hline Groups & $\begin{array}{c}\text { Means of ALT } \\
\text { levels }\end{array}$ & $*$ P-value & $\begin{array}{c}\text { Means of AST } \\
\text { levels }\end{array}$ & $*$ P-value \\
\hline Group I and II & -82.45 & $<0.01^{*}$ & -85.33 & $<0.01^{*}$ \\
\hline Group I and III & -6.46 & 0.078 & -7.34 & $0.042^{*}$ \\
\hline Group II and III & 75.99 & $<0.01 *$ & 77.99 & $<0.01^{*}$ \\
\hline
\end{tabular}

$* P$-value $\leq 0.05$ was considered significant

\section{Discussion}

Diazinon, is a commonly used organophosphorous insecticide. It has been used for the control of soil insects and pests, on ornamental plants, and on fruits, vegetables and field crops. Now it is used to control flies around animal facilities, greenhouses, grounds and public places where food or animal wastes might be accumulated. The undesired effects of pesticides have been recognized as a serious public health concern during the past decades. Our study revealed histopathological alterations by Diazinon in the liver tissue. Diazinon resulted in damage to the hepatocytes and congestion of central veins and sinusoids. Similar findings were observed by other researchers. ${ }^{14}$ Cakici and Akat found that that Diazinon produces vacuoles in the hepatocytes, increases Kupffer and inflammatory cells and promotes congestion of the central veins in mice. ${ }^{7}$ Ezzi et al, in their research also proved that Diazinon causes distortion of portal triads and congestion of central veins and sinusoids. ${ }^{15}$

Diazinon induces histological alterations in the liver by lowering the capacity of antioxidant systems and increasing the levels of free radicals. ${ }^{16}$ Research done by Saraei et al. revealed that inhalation of Diazinon by pregnant mice increased the apoptosis in the developing hepatocytes. ${ }^{17}$

The liver sections of rats belonging to group III showed normal histological structure of the hepatic tissue. Normal arrangement of hepatocytes was observed. The cytoplasm and the nuclei of the hepatocytes revealed no degenerative changes. Sinusoids exhibited normal features. Kupffer cells appeared normal in size. The central veins were not congested. The results correspond with the findings of Malhi et al., who indicated that Mulberry has 
protective effects against paracetamol induced hepatic injury. ${ }^{18}$ Tag suggested that Morus nigra leaf extract exerts hepatoprotective effect against antirheumatic drug methotrexate. ${ }^{9}$

The levels of AST and ALT in the serum are the indices of liver injury. The increased levels of these enzymes indicate severe liver injury. Damage of hepatocytes is reflected by an elevation in the levels of hepatospecific enzymes (ALT and AST). These enzymes are stored in the cytoplasm and are released into circulation after cellular damage. The current study showed that Diazinon produced significant rise in the levels of AST and ALT. Haghightjoo et al. also proved that Diazinon increases level of liver enzymes and decreased total protein and causes the histological alterations in rat liver. ${ }^{19}$

However, Morus nigra produced a significant decrease in the AST and ALT levels, due to its antioxidant properties. Antioxidants protect the cell membrane integrity and prevent enzyme leakage. They help in scavenging the free radicals. ${ }^{20}$ Mulberry extract contains large amounts of tannins, flavonoids, phenols. Therefore, the presence of flavonoids may be responsible for its protective effects on Diazinon induced liver injury in this study. The results also coincide with the observations of Mallhi et al. ${ }^{18}$ Pesticides exert their biological effects mainly through electrophilic attack of cellular constituents with simultaneous generation of reactive oxygen species (ROS). ROS may, therefore, be involved in the toxicity of various pesticides. Pesticide induce oxidative stress leading to generation of free radicals and alteration in antioxidants or oxygen free radical scavenging enzyme systems. ${ }^{4}$ Deniz et al. proved that Morus nigra protects the liver against carbon tetrachloride and it can serve as a novel approach for treating various hepatic problems. ${ }^{21}$ Agha et al. suggested that mulberry juice is rich in antioxidants and it can protect against hepatotoxicity induced by carbon tetrachloride. ${ }^{22}$ Free radical scavenging activity is attributed to the flavonoids mainly quercetin and isoquercitrin found in black mulberry. ${ }^{23}$ Quercetin in the extract increases the expression of antioxidant enzyme system. While, Oleanolic acid enhances the glutathione regeneration capacity and Luteolin inhibits peroxidation of biomembranes. ${ }^{24}$

Limitations: The small sample size and shorter duration of the experiment to observe the effects of Morus nigra can be considered as limitations of our study. Another limitation is that the study was conducted on an animal model, so the results cannot be generalized to a human model, so similar studies on humans are recommended.

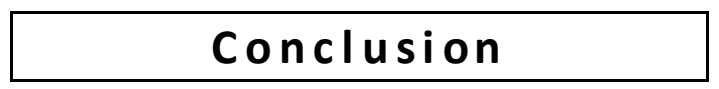

Morus nigra leaf extract protected the liver against Diazinon induced hepatotoxicity in male rats. Therefore, it can be considered as a protective agent against free radical-induced liver damage following exposure to Diazinon. Further clinical trials can be planned to evaluate the effects of Morus nigra on other organs and on the levels of free radicals. Further investigations are needed to explore the mechanism action of Morus nigra against Diazinon toxicity.

\section{References}

1. Slotkin TA, Skavicus S, Seidler FJ. Diazinon and parathion diverge in their effects on development of noradrenergic systems. Brain Res Bull. 2017; 130: 268-73. Doi: 10.1016/j.brainresbull.2017.02.004

2. Ghazala, Mahboob S, Ahmad L, Sultana S, Alghanim $\mathrm{K}$, Al-Misned $\mathrm{F}$, et al. Fish cholinesterases as biomarkers of sublethal effects of organophosphorus and carbamates in tissues of Labeo Rohita. J Biochem Mol Toxicol. 2013; 28(3):137- 42. Doi: 10.1002/jbt.21545

3. Ajibade TO, Oyagbemi AA, Omobowale TO, Asenuga ER, Afolabi JM, Adedapo AA. Mitigation of Diazinoninduced cardiovascular and renal dysfunction by 
gallic acid. Interdiscip Toxicol. 2016; 9(2): 66-77. Doi: 10.1515/intox-2016-0008

4. Nili-Ahmadabadi A, Alibolandi P, Ranjbar A, Mousavi L, Nili-Ahmadabadi H, Larki-Harchegani A, et al. Thymoquinone attenuates hepatotoxicity and oxidative damage caused by Diazinon: an in vivostudy. Res Pharm Sci. 2018; 13(6): 500-508. Doi: 10.4103/1735-5362.245962

5. Karimani A, Heidarpour $M$, Moghaddam Jafari A. Protective effects of glycyrrhizin on sub-chronic Diazinon-induced biochemical, hematological alterations and oxidative stress indices in male Wistar rats. Drug Chem Toxicol. 2019; 42(3): 300-8. Doi: 10.1080/01480545.2018.1497053

6. Ahmadi-Naji R, Heidarian E, Ghatreh-Samani K. Evaluation of the effects of the hydroalcoholic extract of Terminalia chebulafruits on Diazinon-induced liver toxicity and oxidative stress in rats. Avicenna J Phytomed. 2017; 7(5): 454-66. PMID: 29062807

7. Cakici O, and Akat E. Effects of oral exposure to Diazinon on mice liver and kidney tissues: biometric analyses of histopathologic changes. Anal Quant Cytol Histol. 2013; 35(1): 7-16. PMID: 23469619

8. Abdel-Daim MM, Taha R, Ghazy EW, El-Sayed YS. Synergistic ameliorative effects of sesame oil and alpha-lipoic acid against subacute Diazinon toxicity in rats: hematological, biochemical, and antioxidant studies. Can J Physiol Pharmacol. 2016; 94(1): 81-8. Doi: 10.1139/cjpp-2015-0131

9. Tag HM. Hepatoprotective effect of mulberry (Morus nigra) leaves extract against methotrexate induced hepatotoxicity in male albino rat. BMC Compl Alt Med. 2015; 15: 252. Doi: 10.1186/s12906-015-0744y

10. Souzaa GR, Oliveira-Juniora RG, Dinizb TC, Brancob A, Lima-Saraivac SR, Guimarãesa $A L$, et al. Assessment of the antibacterial, cytotoxic and antioxidant activities of Morus nigra L. (Moraceae). Braz. J. Biol. 2018; 78(2): 248-254. Doi: 10.1590/1519-6984.05316

11. Mahmoud ARH, Shalaby NM. Evaluation of hepatoprotective effect of propolis against subchronic Diazinon induced hepatotoxicity. Egypt J. Forensic Sci. Appli. Toxicol. 2018; 18 (4):53-66. Doi: 10.21608/ejfsat.2018.5216.1025

12. Chen H, Pu J, Liu D, Yu W, Shao Y, Yang G. Antiinflammatory and antinociceptive properties of flavonoids from the fruits of black mulberry (Morus nigra L.). PloS One. 2016; 11:153. Doi: 10.1371/journal.pone.0153080

13. Lim HH, Yang SJ, Kim Y, Lee M, Lim Y. Combined treatment of mulberry leaf and fruit extract ameliorates obesity related inflammation and oxidative stress in high fat diet-induced obese mice. J Med Food. 2013; 16(8): 673-680. Doi: 10.1089/jmf.2012.2582.

14. Karimani A, Mamashkhani Y, Jafari AM, Akbarabadi M, Heidarpour M. Captopril Attenuates DiazinonInduced Oxidative Stress: A Subchronic Study in Rats. Iran J Med Sci. 2018; 43(5): 514-522. PMID: 30214104

15. Ezzil L, Haouas Z, Salah I, Sakly A, Grissa I, Chakroun $S$, et al. Toxicopathic changes and genotoxic effects in liver of rat following exposure to Diazinon. Environ. Sci. Pollut. Res. 2016; 23 (11):11163-11170. Doi: 10.1016/j.sjbs.2016.10.013

16. Adampourezare $M$, Sistani $P$, Nemati HH. Protective Effect of Dorema glabrum on Induced Oxidative Stress by Diazinon in Hippocampus of Rat. IJBCRR. 2019; 25(3): 1-7. Doi: 10.9734/ijbcrr/2019/v25i33 0077

17. Saraei F, Sadoughi M, Kaka G, Sadraie S, Foaddodini $M$. Study of the effects of Diazinon on fetal liver in BALB/c mice. Iran Red Crescent Med. J. 2016; 18(4): 1-7. Doi: 10.5812/ircmj.28076

18. Mallhi TH, Qadir MI, Khan YH. Determination of phytoconstituents of $n$-hexane extract of leaves of Morus nigra and evaluation of their effects on biochemical and histopathological parameters in paracetamol intoxicated mice liver. Braz. J. Pharm. Sci. 2018; 54(3):18101. Doi: 10.1590/s217597902018000318101

19. Haghightjoo SA, Shariati $M$, Mokhtari $M$, Moghadamnia D. Effect of Diazinon on functional tests and liver tissue alterations in adult rats. J Gorgan Univ Med Sci. 2019; 21(1): 38-45.

20. Karimi-Khouzani O, Heidarian E, Amini SA. Antiinflammatory and ameliorative effects of gallic acid on fluoxetine-induced oxidative stress and liver damage in rats. Pharmacol Rep. 2017; 69(4): 830-5.

21. Deniz GY, Laloglu E, Koc K, Nadaroglu H, Geyikoglu F. The effect of black mulberry (Morus nigra) extract on carbon tetrachloride-induced liver damage. Arch Biol Sci. 2018; 70(2): 371-378. Doi: 10.2298/ABS1710090 55D 
22. Agha FG, Fyiad AA, El Safi H. Comparative study of the protective role of black berry juice and silymarin against liver damage induced by carbon tetrachloride in rats. J Appl Sci Res. 2012; 8(2): 727-38. Doi: 10.1186/s12906-015-0744-y

23. Elisana Lima Rodrigues EL, Marcelino G, Silva GT, Figueiredo PS, Garcez WS, et al. Nutraceutical and
Medicinal Potential of the Morus Species in Metabolic Dysfunctions. Int J Mol Sci. 2019; 20: 301. Doi: 10.3390/ijms20020301

24. Alamri ZZ. Effect of Luteolin and Quercetin on Thioacetamide Induced Hepatic Fibrosis in Rats. Int. J. Pharmacol. 2019; 15(7): 863-871. Doi: 10.3923/ ijp.2019.863.871 